\title{
In-service Mathematics Teachers' Effective Reflective Actions during Enactment of Social Constructivist Strategies in their Teaching
}

\author{
Lovemore J. Nyaumwe \\ Marang Centre for Maths \& Science Education, University of the Witwatersrand \\ lovemore.nyaumwe@wits.ac.za \\ David K. Mtetwa \\ University of Zimbabwe \\ dmtetwa@education.uz.ac.zw
}

\begin{abstract}
This study documents two case studies of in-service teachers whose reflective actions during teaching belonged to the effective category. Stratified sampling was used to select the in-service teachers whose reflective actions during teaching achieved effective reflection category in the first round of assessments. The sampled in-service teachers were jointly observed by two researchers whilst teaching high school mathematics classes in the second and third rounds of assessment visits to determine their teaching actions whilst enacting effective reflective actions. Classroom observations were followed by post lesson reflective interviews. The in-service teachers' effective reflective actions during teaching were noted as aligning learners' prior knowledge with activities to develop new concepts, sensitivity to learners' needs, using multiple pedagogical methods, and causing cognitive conflicts that facilitated learners' reflections on the solutions that they produced. These findings provide insight into theorising in-service teachers' reflective actions that informs reform on appropriate enactment of social constructivist strategies in mathematics classrooms.
\end{abstract}

\section{Background of the study}

The results of the Third International Mathematics and Science Study (TIMMS) gave rise to a constant search for ways of improving secondary school mathematics learners' achievement throughout the world (Julie, 2004). This search has given rise to raging debates on what pedagogical methods facilitate learner understanding and retention of mathematical knowledge. These debates are guided by teachers' orientations that belong to either the absolutist or problem-solving paradigm. In the absolutist paradigm, mathematics is viewed as a universal static subject whose concepts reside outside human senses. Teachers holding absolutist views demonstrate mechanistic applications of axioms and theorems that they expect learners to accept as indisputable truths.

A criticism that is often levelled against absolutist methods is that they transmit inert mathematical knowledge that learners passively access in restricted contexts. Passive learning of mathematical concepts has potential to limit learner applications of the concepts in a variety of contexts that are different from textbook questions. This criticism has necessitated the advocating of problem-solving instructional reforms in many countries. The problem-solving reforms are informed by social constructivist perspectives. Social constructivist reform encourages classroom environments that provide learners with opportunities to engage in dynamic mathematical activities that are grounded in rich problem-solving mathematical tasks (NCTM, 1991). Teaching in such classrooms encourages learner construction of mathematical knowledge through active cognitive and social engagements using the experiential world 
(von Glasersfeld, 1995). Teacher roles when enacting problem-solving strategies shift from dispensers of mathematical knowledge to coordinating, facilitating, guiding, and providing resources. Teaching and learning mathematics in such classrooms ceases to be learner and teacher convergence on pre-existing truth, to divergence and broadening on what is knowable, doable and viable (Breen, 2005).

Based on Vygotsky's (1978) co-construction theory, the social constructivist perspective advocates that mathematical knowledge is not built by individual learners, but in a wider social context which is linked to learners' environment and cultural activities. Effective teaching in the social constructivist perspective is based on creating opportunities for learners to experience, discuss, discover and socially construct mathematical knowledge using their contexts. Such teaching involves learner active engagements on physical and mental activities that involve interpreting, constructing and reflecting on their decisions in ways that enhance learners to create viable mathematical knowledge through personal experiences, observations, discoveries, and interactions with other learners and the local environment. This study is focused on in-service teachers' effective reflective actions as they enact some social constructivist tenets in their teaching. To achieve effective reflection category, the in-service teachers integrate problemsolving and absolutist teaching strategies at appropriate stages of lesson development in order for learners to develop both conceptual and procedural understanding of mathematical concepts and process skills.

Success in complementing problem solving with absolutist teaching strategies requires in-service teachers' effective reflections. Reflection is the means through which in-service teachers assess the effectiveness of their instructional decisions through a critical analysis of what happened, why it happened and what they could do differently to improve their teaching performance (Galvezl-Martin, 2003). Dewey (1933) noted that during reflection teachers examine their teaching performance by critically analyzing what, how and why they did what they did in their teaching with an ultimate goal of improving learner understanding.

Effective reflections during teaching enhances in-service teachers to consciously think about pedagogical actions at the time they are being enacted, interpret learner actions, and appropriately shape successive teaching using multiple pedagogical approaches in order to promote learner understanding (Schon, 1987). The process of formulating effective reflective actions during teaching renders the enterprise of teaching a complex one (Even, 2005). The complexity of teaching arises through involvement of in-service teacher self-critical through questioning their interpretation of learners' actions in ways that necessitate them to frame and reframe their assumptions about learners' learning capacities and problematising their teaching. Making effective reflective actions during teaching that enables in-service teachers to balance and respond to learners' cognitive, psychological and social needs is demanding. It calls for ability to apply singly or a combination of qualitatively distinct kinds of reflections such as technical, deliberate and critical reflection to given instructional situations as they unfold in the classroom (Hatton \& Smith, 2006). In-service teachers' effective reflective actions during their teaching can facilitate learners to construct mathematical knowledge in ways that enhances them to apply the learnt concepts in solving routine and non-routine problems.

This study was in response to Richardson's (2003) request for more theory building in social constructivist pedagogy. This request was based on the fact that social constructivism is a theory of learning and that scanty literature is available on social constructivist teaching. High school mathematics classroom contexts were used in attempting to achieve the goal of theory building on social constructivist pedagogy. High school contexts were chosen for this study due to in-service teachers' concerns that mathematical concepts at this level were too abstract to develop them from learners' everyday contexts. Analysing in-service teachers' ability to critically reflect on their decisions and actions during teaching makes it possible to use concrete examples from a lesson to assess effective reflective actions drawn from their teaching practice. The assessment facilitates theorising how the effective in-service teachers succeeded in enacting social constructivist approaches in their teaching. In pursuing the goal of the study, the following research question was posed: What are the effective reflective actions that in-service mathematics teachers on full-time teaching practice of their programme are capable of achieving when implementing social constructivist strategies in their teaching? Answers to the research question may provide insight that can inform teacher professional development programmes on enacting social constructivist strategies that are emphasized in mathematics curricula reforms. 


\section{Conceptual framework from a theoretical perspective}

Teaching mathematics is a complex enterprise that sometimes involves teachers to make effective and ineffective reflections. Schon (1987) portrayed reflection that is embedded in action. He concluded that teachers frame and reframe their teaching, test various interpretations that they infer from learning contexts and modify their teaching actions accordingly. Schon (1987) perceived teacher reflection as taking place during and after teaching calling them reflection-in-action and reflection-on-action respectively. Reflection-in-action refers to the process of enacting pedagogical strategies, interpreting and analyzing learner outcomes with a view to improve teaching at the time it is taking place (Schon, 1987). In-service teachers perform reflective actions during teaching that are informed by their theories-in-use. After teaching a lesson in-service teachers engage in reflection-on-action. Reflection-on-action takes place when an in-service teacher mentally reconstructs an instructional arena long after teaching a lesson in order to analyse actions and their outcomes (Schon, 1987).

Effective reflection involves wise choices of resources, pacing and sequencing content, creating conducive classroom environments that promote learner participation, challenging, and extending learner thinking (Even, 2005). Teacher effective reflections enable learners to develop conceptual understanding of the process skills that enable learners to individually or collectively develop a repertoire for making constructions that can concur with viable mathematical knowledge (Davis, 1990). This is possible because teacher effective reflections involve learner engagement in constructive, self-regulated, goaloriented, situated, collaborative, and cumulative process of building mathematical concepts, and making meaning out of them (Schelfhout, Dochy, Janssens, Struyven, \& Gielen, 2006).

In-service teacher engagements in reflection facilitate their effectiveness in enacting social constructivist tenets. The social constructivist theories have a basis in philosophical and psychological backgrounds. For instance, Ahmed in Wheatley (1991) noted that effective learning of mathematics can be achieved through discourse, experimenting, discovering, inventing, discussing and reflecting. In proposing learning through interactions, observations and negotiations Vygotsky in Ferguson (2005) proposed the zone of proximal development (ZPD). ZPD theorizes that group learning has potential to contribute more learners' understanding than what learners are capable of constructing as individuals. The argument of social learning is that cognition and intelligence are not properties of individual learners but arise from interactions with other learners in the learning environment. Active construction of mathematical knowledge in social contexts facilitates the development of conceptual understanding and transferability of the concepts to applications in a variety of contexts.

To facilitate learners' social interactions in mathematics classrooms, learning is made problematic through provisions of authentic problem-solving tasks existing in the learners' environment. Such tasks can intuitively be approached by learners using trial, error, and success. Enactment of social constructivist strategies in the classroom requires authentic learning environments that facilitate learner building of new mathematical knowledge from their prior knowledge. Such learning facilitates learners' applications of mathematical concepts in a variety of contexts in the classroom and their environments. Absolutist methods of demonstrating mathematical concepts for learners to reproduce them restrict learners' success to solving routine problems. Complementing absolutist approaches with problem-solving approaches is an ideal strategy that has potential to maximize learners' mastery of procedural and conceptual mathematical knowledge and skills. For instance, the complementarities may proffer effective learning when concepts that are abstract or difficult to connect and derive from learners' environment are demonstrated by in-service teachers.

Complementing problem-solving approaches with absolutist methods requires effective reflections at appropriate stages of a lesson that attains different reflection categories in the process. This is the essence of this study - to assess effective reflective actions that some in-service mathematics teachers were capable of achieving when enacting social constructivist strategies in their teaching during full-time teaching practice of their programme.

\section{Design of the study}

The in-service teachers who participated in this study were enrolled in a two year full-time programme that upgrades their content and professional knowledge to teach mathematics at high school $\left(16^{+}\right.$year- 
old learners) level. The in-service teachers were on a four-week school attachment part of their BSc Ed programme to practice implementation of social constructivist pedagogies. In-service teachers' learning to enact social constructivist pedagogical strategies in their teaching is a situated practice because it takes place in a particular location shaped by a unique set of personal, institutional, and social factors.

In-service teachers' effective reflective actions during teaching that this study focused on are those belonging to the good reflection category. Case studies of two in-service teachers, attached at different schools, who achieved effective reflection categories in the first round of assessment visits by faculty members, were assessed by the two researchers in the second and third rounds of assessment visits. This means that stratified sampling was the method used to select the two in-service teachers who provided data for this study. Given the sampling criteria, a sample of two out of a cohort of 14 in-service teachers studying mathematics as a major study is normal. Power, Clarke and Hine (2002) argued for small sample size of high level teacher reflection because achievement of effective category of reflective actions during teaching is difficult to attain for most in-service teachers. This category of reflective actions during teaching is hard to achieve because in-service teachers are usually pre-occupied with processes of enacting new pedagogical reform that they sometimes overlook their process of learning how to teach. This observation makes the sample large enough to provide data that can be used to theorise effective reflective actions of in-service teachers implementing reform on social constructivist teaching strategies.

In-service teachers' ability to make effective reflective actions during teaching in response to learners' needs can be detected through assessments of lessons and post lesson reflective interviews that produce texts from illustrative episodes and elaborations of their responses to learners' actions and needs. Two researchers who were also mathematics education lecturers assessed the in-service teachers' teaching. The assessments were conducted after reaching agreement on what constitutes effective and non-effective reflective actions during teaching. Three agreed common areas of focus to make valid and uniform assessments by the researchers were social constructivist tenets of learner interactions, pedagogy and student learning. Assessments on learner interactions focused on (a) learner-learner interactions, (b) learner-in-service teacher interactions, (c) learners' explorations, (d) learners' discussions and construction of mathematical knowledge, and (e) learners' reporting of group activities. On pedagogy the assessments focused on the tenets of (a) multiple use of teaching methods, (b) clarity of instructions, (c) logical progression of activities, and (d) assessment of learners' understanding. On student learning the following tenets were assessed (a) use of learners' prior knowledge, and (b) suitability of activities for learner construction of mathematical knowledge.

During the joint assessment the two researchers made detailed field notes on each of the two in-service teachers' reflective actions during teaching. They provided evidence from a classroom episode of conclusions that they made on instructional and reflection competencies achieved by an in-service teacher. Post lesson reflective interviews were held after assessment of teaching. Their purpose was to enable the in-service teachers to elaborate some of the decisions that they made during teaching. To increase the validity and reliability of interpreting the teaching and field notes produced, the assessed lessons were video taped. The video tapes validated the researchers' interpretations by providing concrete evidences from lessons that were used to ascertain teaching actions and contexts during post lesson reflective interviews. The post lesson reflective interviews were audio taped and transcribed so that the two researchers could use the transcriptions to assess the effective reflective actions shown by an inservice teacher. Audio and video tapes facilitated consensual agreement on effective reflective actions during teaching exposed by the in-service teachers during post-lesson reflective discussions.

A common understanding of effective and ineffective teaching practices provided insight on the extreme ends of a continuum on which reflective actions during teaching could be scored. Realizing that typical teaching practice combine both effective and ineffective decisions, gave rise to satisfactory reflective actions during teaching as falling in the middle of the effective to non-effective decision continuum. Whilst effective reflective actions during teaching are relatively easy to identify from learners' responses to instructional decisions and actions, it is not relatively easy to identify ineffective reflective actions during teaching. This is so because reflection is an abstract concept that cannot be identified as out rightly ineffective but can be unsatisfactory. Based on this argument, the tacit nature of reflection necessitated that scoring of in-service teachers' reflective actions during teaching be scored on the continuum unsatisfactory, satisfactory and effective categories. An example of an unsatisfactory reflection category 
is ignoring learners' misconception in favour of right or wrong response. In the satisfactory reflection category an example is teaching that does not cater for learners' differentiated needs. An example in the effective reflective actions during teaching category is relating content to the existent reality of learners and other subjects that they study.

\section{Results}

The results from each of the two case studies are presented separately in order to provide cross-case analyses that can show commonalities and differences between them. Verbatim researchers' extracts from classroom episodes are presented first, followed by post lesson reflective interview intercepts. Pseudonyms are used for the in-service teachers in order to protect their identities.

Monica taught the concept of integration as a limit of a sum using the trapezium rule to estimate the area under a curve. She used the discovery method in which pairs of learners were asked to find the area under the curve $y=x^{2}$ between $x=0$ and $x=1$. First, learners calculated the definite integral of $\int_{0}^{1} x^{2} \mathrm{~d} x$ and found it to be $\frac{1}{3}$ or 0,33 . Later, the learners looked for a method that could produce the same area. The learners debated alternative methods to the definite integral approach. Monica moved round the classroom to assess learners' progress and approaches they were using. She gave hints to struggling groups that provoked insight into recalling relevant prior knowledge that helped them to approach the task. After 15 minutes of pair-work, the learners were asked to stop their group-work in order to discuss the ideas that they generated in their groups with the rest of the class members.

During class discussion learners were picked to come to the board to contribute a step towards the solution of the problem. The first learner chosen drew the graph of $y=x^{2}$ and divided the interval $0 \leq x \leq 1$ into five equal sub-intervals. Learners struggled on what to do next. Another learner volunteered to go to the board and calculated the width of each sub-interval. The width was found it to be $\frac{1}{5}$. A fourth learner calculated the successive heights of the rectangles in the interval $y=x^{2}$ between $x=0$ and $x=1$. These were found to be $\left(\frac{1}{5}\right)^{2},\left(\frac{2}{5}\right)^{2},\left(\frac{3}{5}\right)^{2},\left(\frac{4}{5}\right)^{2}$. Another learner multiplied the width $\left(\frac{1}{5}\right)$ by the height of each rectangle in the interval.

The total area of the rectangles in the interval was found to be 0,24 . Monica asked the learners to explain why the solution was different from 0,33 that was obtained using the definite integral approach. The learners assessed the validity of the new solution, reviewed the steps and method used but could not identify flaws in them. Monica drew the attention of the learners to the rectangles of the sub-intervals on the graph in order for them to see some triangles whose areas lay outside the area calculated. This helped the learners to deduce the reasons why the solution from the definite integral was larger than the one obtained from adding five rectangles in the interval. Later the learners were asked to divide the interval into ten equal parts and find the sum of the areas of the rectangles formed. This area was found to be 0,285 which is closer to 0,33 than 0,24 .

The learners were asked to think abstractly in order to get a more accurate area than the ones they got from the physical graph on the board. One learner suggested that the more the number of rectangles in the interval, the thinner the widths, and the better the rectangles approximated the area under a curve between the given limits. This generalisation was deduced from the fact that thinner rectangles formed smaller number of triangles that lay between the curve and tops of the rectangles in the interval. This means that the tops of the rectangles were as close as possible to the curve which minimised the area between the curve and the rectangles that is not included in a sub-interval. As the number of rectangles got very large (goes to infinity), the width of the rectangles in a sub-interval got small to coincide with the tangent of a curve.

To link the physical and the abstract methods, Monica extended learners' generalisation to an algebraic algorithm. This was done for the interval $0 \leq x \leq a$ when the interval is divided into $n$ equal parts. This 
formed sub-intervals of width $\frac{a}{n}$ and $n-1$ rectangles. The heights of the rectangles in the interval were $\left(\frac{a}{n}\right)^{2},\left(\frac{2 a}{n}\right)^{2},\left(\frac{3 a}{n}\right)^{2}, \ldots,\left(\frac{(n-1) a}{n}\right)^{2}$

The areas of the rectangles in the sub-intervals were calculated thus:

$$
\frac{a}{n} \times \frac{a^{2}}{n^{2}}+\frac{a}{n} \times \frac{4 a^{2}}{n^{2}}+\frac{a}{n} \times \frac{9 a^{2}}{n^{2}}+\ldots+\frac{a}{n} \times \frac{(n-1)^{2} a^{2}}{n^{2}}=\frac{a^{3}}{n^{3}}\left\{1+4+9+\ldots+(n-1)^{2}\right\} .
$$

The right hand side of the generalisation (sum of squared numbers) was summed to

$\frac{a^{3}}{n^{3}} \times \frac{1}{6}\left(2 n^{3}-3 n^{3}+n\right)=\frac{a^{3}}{6}\left(2-\frac{3}{n}+\frac{1}{n^{2}}\right)$. When $n$ is very large (as $n$ tends to the infinite), $n \rightarrow \infty$, $\frac{a^{3}}{6}\left(2-\frac{3}{n}+\frac{1}{n^{2}}\right) \rightarrow \frac{a^{3}}{3}$, since $\frac{3}{n} \rightarrow 0$ and $\frac{1}{n^{2}} \rightarrow 0$. This general form concurs with the definite integral of $\int_{0}^{1} x^{2} \mathrm{~d} x=\frac{1}{3}$ for the case when $a=1$. This general part enabled learners to realise the need for as many divisions as possible on a sub-interval for a more accurate approximation. This realisation prompted one learner to ask the question "when does a tangent of a curve at a point coincide with sides of rectangles approximating the curve". Learners theoretically visualised the answer to the question when there were infinitely many rectangles under the interval of a curve.

During the post lesson reflective interview Monica reflected on her interactions with the learners in this way:

I let learners to figure out on their own what method to use. I wanted them to think eh, eh, eh and design their own approaches. As was expected, the learners started off from the definite integral that was familiar to them before exploring a different method. I mixed demonstrations and... active learner activities in order for the learners to recall previously learnt concepts such as definite integrals, summation of squared consecutive numbers, as well as make selective choices on the concepts to use (Post lesson reflective interview with Monica, July 2006).

Another in-service teacher, Cecil, was assessed teaching the concept of probability of two independent events. For instance, he asked learners to calculate the probability of getting a sum of 10 when two dice are thrown. He correctly assumed that learners were not familiar with the concept of dice as they were not commonly used in their environment. He showed the learners a die and asked them to discuss its properties. After the discussion, the learners pondered on how to represent the outcomes of the two thrown dice and how to get a sum of 10 from the possible numbers thrown. After ten minutes of learners' discourse on a plan to get the totality of the outcomes from which to draw the sample space that answers the question, Cecil gave the learners some clues. He showed them a possible outcome event after throwing the two dice once.

Learners were later asked to write all the possible ordered pairs of events when two dice are thrown together. At first the learners wrote the possible combinations as random numbers without being mindful of the systematic pattern that could ensure that all possible outcomes are noted. Some clues were given for learners to realise that the events from the two dice can be represented by the adjacent sides of a square, one die representing the length and the other die the width. The learners labelled the adjacent sides of the square 1 to 6 representing the possible outcome on each of the two dice when thrown. The ordered pairs of the point of intersections of perpendicular and horizontal lines passing through the six numbers on the face of each die were marked as coordinate points. From the constructed outcome table, learners were asked to identify the ordered pairs that could provide a sum of 10 . The learners identified this sample space as $(4,6),(5,5)$ and $(6,4)$. The learners discussed whether $(4,6)$ and $(6,4)$ were different. The concepts of permutations and combinations helped the learners to understand that the order of the numbers was important as they were drawn from different dice. 
During the post lesson reflective interview Cecil reflected on the lesson as follows:

Dice are not common in the learners' environment ... that's why I showed them a sample. I gave learners opportunities to figure out for themselves how to construct an outcome table and to identify a sample space with combinations of ... numbers adding up to 10 . I used guided discovery to enable learners to draw the outcome table in order to show the sample space of pairs adding up to 10 . This necessitated a combination of demonstrations and learner explorations that I used in the lesson (Post lesson reflective interview with Cecil, July 2006).

\section{Discussion}

The results of this study indicate that the in-service teachers' effective reflective actions during teaching resulted from aligning learner prior knowledge with new content, integrating problem-solving and absolutist teaching methods at appropriate stages and probing learners' thinking. The integration of instructional approaches from two diverse paradigms complemented the strengths and weaknesses of each approach. The in-service teachers in this study based their choices of teaching strategies and reflective actions on their assumptions and conceptions of teaching and learning mathematics based on their concerns for learner understanding. The assumptions and instructional conceptions that they held about effective implementation of social constructivism approaches revealed the mental maps that determined their teaching actions. Similar to conclusions made by (Smith, 2001) mental maps determined an inservice teacher's instructional actions more than pedagogical theories. Mental maps on how students learn mathematical concepts and skills facilitated in-service teachers' integration of absolutist and constructivist teaching approaches.

The in-service teachers integrated multiple teaching methods to maximize learner processing of the concepts of integration and outcome tables that they were learning. For instance, Monica deduced the trapezium rule from learner prior knowledge of concrete areas of rectangles observed on a graph, to abstraction using calculus concepts such as definite integral and summation of series. The mental maps that the in-service teachers constructed of how learners could comprehend mathematical concepts and procedures facilitated their appropriate reflective actions to decide when to guide learners or when to let them struggle. For instance, the guidance that Cecil gave learners on dice activated them to make connections between their prior knowledge on coordinates and the concepts of finding the probability of getting a sum of 10 when two dice are thrown. Structured feedback was given at the opportune moments to facilitate learners to discuss the sample space for getting a sum of 10 in meaningful ways. On the other hand, Monica's effective reflective actions during teaching were portrayed through multiple representation of content that facilitated learner understanding. She used graphical representations in order for learners to see the small triangles that were lying outside the rectangles that influenced the estimated area under a curve. Visualisations of the outlying areas facilitated the learners' use of theoretical discussions that extended their understanding from physical observations to abstraction where the concept of infinite sub-divisions was used to obtain a more accurate area. Combining physical representations of mathematical generalisations with their theoretical algebraic explanations facilitated learners to gain both conceptual and procedural understanding of the trapezium rule in ways that facilitated their understanding the rule gives an approximation rather than an accurate area in an interval of a curve.

Monica also made effective reflective decisions on when to refer to a drawn graph and when to allow learners to think abstractly in order to formulate and theorise generalisations. This allowed learner explorations and collaboration on making deductions through struggling with mathematical tasks. Learner successes were possible because Monica appropriately aligned mathematical tasks with learner prior knowledge. As a result of the alignment she probed learner thinking without reducing the complexity of the task (Henninsen \& Stein, 1977).

Appropriate alignment of learner prior knowledge and new concepts facilitated their reviewing of previously covered concepts and applying them in new situations. As explained by Moll (2002) learning is a process of recollection where new concepts grow from existing ones. The use of prior knowledge made learners develop cognitive conflicts when they noticed discrepancies in the solutions produced by procedures familiar to them. For instance, in Monica's class, learners recalled their knowledge of definite 
integrals to calculate the area under the curve $y=x^{2}$ between $x=0$ and $x=1$ and found it to be 0,33 . When they used five rectangular sub-intervals of the region to estimate the area, they found it to be 0,24 which was different from the previously found area of 0,33 . The differences in the definite integral and rectangular estimation solution created cognitive conflicts that facilitated learners to reflect on the methods that they used and checking for possible computational errors or any inconsistencies that might have influenced the solutions to be different. Reflection in pursuit of effective and manageable balance between possibly conflicting solutions is necessary for learners to assess the viability of their solutions in the light of constraints of the question (Davis, 1990; Schelfhout et al., 2006).

When the learners found no inconsistencies or computational errors in the solution strategies used, they were prompted to think of possible explanations to account for the differences noticed. Monica probed learners at opportune times to guide their resolving of the cognitive conflict created. The probing enabled the learners to refocus their attention on the curve showing the interval divided into sub-sections. The refocus facilitated learners to notice that there were some overlapping triangles between the top of each rectangle in a sub-interval whose areas were not calculated. This observation prompted the learners to generalise that the more the sub-sections dividing the interval, the more accurately the areas of the possible rectangles approximate the area under a curve. To reinforce and formalise learners' intuitive generalisations, Monica developed the learners' ideas theoretically using an algebraic approach. The algebraic approach facilitated learners to clarify the cognitive conflict that was created by the discrepancies in the solutions 0,24 and 0,33 and linking their informal generalisation with a formal mathematical generalisation. The algebraic algorithm also enhanced learners to connect observations on a graph with their abstract notions. This approach enabled learners to develop deep understanding of the theory of infinity from a theoretical perspective to a practical one when applied to physical situations of infinitely many rectangles fitted in a curve until a slope of the curve (tangent) becomes a side of a rectangle. For instance, a learner who asked, "when does a curve and a side of a rectangle coincide?" was engaged in deep thinking of the possibilities of infinitely many rectangles and trying to visualise them on a physical diagram. Learners' questions, cues, or actions influenced the interactions between the learners and the in-service teachers.

The two in-service teachers' instructional strategies involved enactment of discovery teaching methods. The methods were enacted through posing problematic questions and letting learners pondering on how to solve them. The discovery methods were implemented in order to facilitate learners to build new concepts from their prior knowledge. To enable learners to recall relevant prior knowledge that was useful to build new ones, the learners were often asked to answer questions in pairs. Pair-work designs were used based on an understanding that social learning can promote argumentation that can generate multiple perspectives on how to solve mathematical problems. Argumentation in the in-service teacher's mathematics classes enhanced learners' explorations, making connections and generalisations that engaged them in recalling their prior knowledge that was used at appropriate stages of concept development. For instance, Monica's learner involvement in the development of the trapezium rule enabled the learners to think deeply, reason logically to connect concepts from a physical graph in order to construct an algebraic formula of the trapezium rule. Discourse in social learning settings facilitated learners to review their understanding of some mathematical processes, modify them in light of the reasoning or evidence provided by peers and extend them to new understanding which was often at a deeper level. For instance, the debates on whether $(4,6)$ and $(6,4)$ represented different events when two dice are thrown invoked learners' reviewing their knowledge of permutations and combinations, their generalised forms and applications in probability problems.

Effective reflective actions during in-service teachers' teaching were influenced by their alertness to events occurring in a classroom and sensitivity to learners' actions (verbal or non-verbal) and questions. For instance, Monica's sensitivity to a learner who asked the question on tangent of a curve coinciding with sides of rectangles. Listening to learner concerns is an essential social constructivist tenet for three purposes of evaluative, interpretive and hermeneutic listening. Evaluative listening involves assessing the viability of a learner's thought processes, while interpretive listening involves assessing learners' sensemaking in order to determine their understanding or sources of possible misconceptions. Hermeneutic listening involves a dialogue that interrogates the taken-for-granted and the prejudices that frame learners' perceptions and actions (Maoto \& Wallace, 2006). In-service teachers' sensitivities to how learners process new information in order to understand it influenced their reflective actions category during teaching. 


\section{Conclusion}

Although conclusions were made based on two case studies presented in this study, it seems possible to explore these conclusions further on a larger sample in other contexts. The in-service teachers' effective reflective actions during teaching were shown in integrating problem-solving and absolutist teaching approaches in order to meet learners' needs, listening carefully to learners' ideas, deciding appropriate times to provide information or when to let learners struggle and orchestrating discussions among learners. Implementing multiple pedagogical strategies in response to learners' different learning styles and rephrasing learners' explanations to concur with formal algebraic mathematical language also showed effective reflections during teaching. As also observed by Even (2005), effective reflective actions during teaching facilitated the in-service teachers to make wise choices of resources, pedagogical strategies, deciding the pace of instruction, challenge and extend learners' thinking.

This study again highlights some of the challenges that in-service teachers experience when implementing innovative social constructivist teaching practices. In-service teachers' implementation of new pedagogical strategies in real classroom contexts showed potential to narrow their theory-practice gap of social constructivist teaching approaches and integrating them with absolutist teaching strategies in order to maximize learner understanding. Findings from this study provide teacher teachers and in-service teachers with insight to debate, critique, reflect, and extend theories on designing in-service teacher programmes that offer opportunities to build personalized knowledge and skills of how to effectively implement social constructivist approaches in their teaching.

\section{References}

Breen, C. (2005, January). Promising practices in teaching and learning. Paper presented at the $13^{\text {th }}$ Annual Conference of the Southern Africa Association of Research in Science, Mathematics and Technology Education. Windhoek, Namibia.

Davis, R. B. (1990). Constructivist views on the teaching and learning of mathematics. Reston, VA: National Council of Teachers of Mathematics.

Dewey, J. (1933). How we think: A restatement of the relation of reflective thinking to the educative process. New York: D.C. Heath.

Even, R. (2005). Integrating knowledge and practice at Manor in the development of providers of professional development for teachers, Journal of Mathematics Teacher Education, 8, 343-357.

Ferguson, J. W. (2005). Two cases of college instructors' applications of constructivist principles. College Quarterly, 8(3), Retrieved on November Julie, 2006, from http://www.senecac.on.ca/quarterly/2005-vol08summer/betts.html.

Galvezl-Martin, M. (2003). Reflective teaching, reflective practice, and ...what else? Retrieved on April 11, 2006, from http://www.fate1.org/libraqry/ejournal/2003/15_galvez-martin.doc.

Hatton, N., \& Smith, D. (2006). Reflection in teacher education: Towards a definition and implementation. Retrieved on April 11, 2006, from http://alex.edfac.usyd.edu.au/LocalResource/Study1/hattonart.html.

Henningsen, M., \& Stein, M. K. (1997). Mathematical tasks and student cognition: Classroom-based factors that support and inhibit high-level mathematical thinking and reasoning. Journal for Research in Mathematics Education, 28(5), 524-549.

Julie, C. (2004). Can the ideal of development of democratic competence be realized within realistic mathematics education? The case of South Africa, The Mathematics Educator, 14 (2), 34-47.

Maoto, S., \& Wallace, J. (2006). What does it mean to teach mathematics for understanding? When to tell and when to listen. African Journal of Research in Mathematics, Science and Technology Education, 10 (1), 59-70.

Moll, I. (2002). Clarifying constructivism in a context of curriculum change. Journal of Education, 27, 5-32.

National Council of Teachers of Mathematics. (1991). Professional standards for teaching mathematics. Reston, VA: NCTM.

Power, A., Clarke, M., \& Hine, A. (2002, December). Internship learning connects the dots: The theory and practice of reflection. Paper presented at the AARE Conference. Brisbane.

Richardson, V. (2003). Constructivist pedagogy. Teachers College Quarterly, 105(9), 123-154. 
Schelfhout, W., Dochy, F., Janssens, S., Struyven, K., \& Gielen, S. (2006). Towards an equilibrium model for creating powerful learning environments. Validation of a questionnaire on creating powerful learning environments during teacher training internship. European Journal of Teacher Education, 29(4), 471503.

Schon, D. (1987, April). Educating the reflective practitioner. Paper presented at the meeting of American Educational Research Association. Washington, DC.

Smith, M. K. (2001). Donald Schon: Learning, reflection and change. The encyclopaedia of informal education. Retrieved on December 2, 2006, from www.infed.org/thinkers/set-schon.htm.

von Glasersfeld, E. (1995). Radical constructivism: A way of knowing and learning. Washington D. C.: The Falmer Press.

Vygotsky, L. S. (1978). Mind in society: The development of higher psychological processes. Cambridge, MA: Harvard University Press.

Wheatley, G. H. (1991). Constructivist perspectives on science and mathematics learning. Science Education, $75(1), 9-21$. 